\title{
Teacher Perspectives on Peer-Peer Collaboration and Education Technologies in Rural Tanzanian Classrooms
}

\author{
Judith, U, Uchidiuno \\ Human Computer Interaction \\ Institute, Carnegie Mellon University, \\ Pittsburgh, PA
}

\author{
Ken, R, Koedinger \\ Human Computer Interaction \\ Institute, Carnegie Mellon University, \\ Pittsburgh, PA
}

\author{
Amy, E, Ogan \\ Human Computer Interaction \\ Institute, Carnegie Mellon University, \\ Pittsburgh, PA
}

\begin{abstract}
Teachers' perspectives are critical for understanding classroom culture. They create and enforce rules in classrooms and are responsible for educating students using methods that they perceive to be most effective. Therefore, creating supplementary education technologies without understanding teachers and the culture they promote may lead to interventions that are underutilized or ineffective. Our research specifically investigates how technologies that foster student collaboration fit into teachers' views of learning in a rural context with limited existing collaboration scaffolds. We interviewed 24 teachers and observed 39 classrooms in a rural Tanzanian village to understand how teachers value peer-peer collaboration in their teaching practice, and the unique challenges they face educating students in rural classroom settings. We uncover insights that inform the design and deployment of supplementary education technologies to support teachers in rural Tanzania and similar demographics.
\end{abstract}

\section{CCS CONCEPTS}

- Applied computing $\rightarrow$ Computer-assisted instruction.

\section{KEYWORDS}

Early literacy, educational technologies, Sub-Saharan Africa, peerpeer collaboration

\section{ACM Reference Format:}

Judith, U, Uchidiuno, Ken, R, Koedinger, and Amy, E, Ogan. 2021. Teacher Perspectives on Peer-Peer Collaboration and Education Technologies in Rural Tanzanian Classrooms. In ACM SIGCAS Conference on Computing and Sustainable Societies (COMPASS) (COMPASS '21), June 28-7uly 02, 2021, Virtual Event, Australia. ACM, New York, NY, USA, 13 pages. https://doi. org/10.1145/3460112.3471939

\section{INTRODUCTION}

When researchers conduct classroom studies with easily accessible groups, e.g. students in urban cities, gaining insights on classroom culture and teaching practices from teachers is feasible. However, in rural or remote locations with limited infrastructure, access to classrooms can be very difficult. To compensate for these accessibility difficulties, researchers often depend on other heuristics

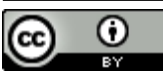

This work is licensed under a Creative Commons Attribution International 4.0 License.

COMPASS '21, fune 28-July 02, 2021, Virtual Event, Australia

(C) 2021 Copyright held by the owner/author(s)

ACM ISBN 978-1-4503-8453-7/21/06.

https://doi.org/10.1145/3460112.3471939 such as systems-based theories (e.g. Hofstede's index) and unrelated research studies conducted in proximal geographical locations to provide insights on the teaching and classroom culture. Based on Hofstede's index values, researchers would expect teachers in Tanzania to have the sole authority in the classroom (high power distance), and that they highly encourage student collaboration in their classrooms (low individualism). However, other research studies from the region such as $[25,33]$ report communication is primarily teacher-dominated with little room for collaboration; even when more time is allowed for lectures, the teachers generally talk for longer rather than incorporating collaborative practices such as group work. Students generally speak up only when called upon or instructed to do so, or to report conflicts with other students; when they initiated conversations unprompted, the teachers either ignored or silenced them. Stambach [33] aptly names her paper based on a direct quote from a teacher, "Here in Africa, We Teach; Students Listen", to underscore this teaching culture. Other studies provide evidence that collaborative behaviors varies depending on pedagogical context - in our own prior work [38,39], we found that students in rural Tanzania collaborated with one another only when their teacher was absent from class.

Over the last two decades, researchers have put forward frameworks intended to guide the incorporation of culture into the design of education technologies. Each of these frameworks privileges a particular theoretical perspective, which naturally results in making certain trade-offs between scalability and learner-fit to design appropriate technology solutions. For instance, technologies based on Hofstede's system of values take a parameterization approach which involves identifying high-level factors on which cultures differ, assigning students to parameter values for different factors based on their demographic information (e.g., their home country), and presenting them with interfaces and learning content that match their expected cultural dispositions.

Such system-based theories, however, assume a monolithic culture even in countries such as Tanzania with a wide variety of languages and cultures. Also, research studies on these value systems are conducted few and far between and thus may not account for changes that may have occurred over time, particularly in remote areas. Insights from [38] suggest that researchers follow an approach that prioritizes learner fit to effectively design learning interventions for this demographic. And yet, high-level insights gleaned from systems approaches may provide a lens through which to explain classroom phenomena and better support designing for learner fit.

Our research contributes to the Human-Computer Interaction, Learning Sciences, and ICT4D scientific communities. Our research study draws from systems of values approaches but applies the 
"Multiple Cultural" framework as described by Lyn Henderson [16] that argues for an "inverted curriculum approach" that designs a topic from an emic perspective without harming the pedagogical and cognitive learning goals. It specifically explores the role of the instructor and examines how teachers perceive and incorporate peer-peer collaboration in their teaching practice. Peer-peer collaboration is of particular interest in part as previous studies show that adults may not always be available to support learning in rural areas in Tanzania [24, 25]. As an instructional tool, peer-peer collaboration has been shown to increase test scores and cognitive activity over individualized learning settings in research in overrepresented cultural contexts $[15,34,40]$. Our research explores the possibility of creating learning technologies that foster peer-peer collaboration in primary schools in rural Tanzania, and how teachers can potentially integrate these technologies into their teaching practice. We interviewed teachers and observed classrooms from four primary schools in a rural Tanzanian village to investigate the following research questions:

- RQ 1: What are the socio-cultural ideologies that influence teachers' disposition towards peer-peer collaboration in rural Tanzania?

- RQ 2: How are peer-peer collaborative practices demonstrated (if at all) in rural Tanzanian classrooms?

- RQ 3: What challenges and opportunities do teachers and students experience in this learning context that might impact the deployment of peer-peer collaborative technologies?

\section{BACKGROUND}

\subsection{Defining the characteristics of different cultural groups}

One of the most popular approaches to defining characteristics of different cultural groups is a system of values framework that consists of identifying universal dimensions of the major orientations of cultural groups so as to develop group-specific models, thus providing an easy method for cross-cultural comparisons and assessments, and for potentially explaining cultural specifics. Universalisms are genuine characteristics of human beings supposedly shared by a wide cluster of (if not all) cultural groups. Group specifics are characteristics peculiar to cultural groups in that they are understood or endorsed by an important portion of insiders and unknown or considered external by outsiders. At present, the most popular system of values results from the analysis of a large-scale cross-national survey from a tradition of Education and Organization Management. Between 1968 and 1972, Hofstede surveyed more than 100,000 employees of the IBM Cooperation in 72 different countries [17, 18]. The cultural dimensions found were expanded to six dimensions by 2011 and represent one scientific basis of people's understanding and interpretation of cultural differences.

Hofstede's framework computes numeric scores for a country along the following five dimensions: a) power distance (PDI: "the extent to which the less powerful members of organizations and institutions (like the family) accept and expect that power is distributed unequally"), b) individualism/collectivism (IDV: the degree to which individuals feel indebted to themselves vs the group as a whole), c) masculinity/femininity (MAS: "the distribution of roles between the genders", and a preference of competition vs harmony within groups), d) uncertainty avoidance (UAI: "a society's tolerance for uncertainty and ambiguity"), and e) long term orientation (LTO: referring to a general interest for "virtue regardless of truth"). Figure 1 presents scores of these dimensions comparing Tanzania to the United States. It is important to acknowledge that while Hofstede's dimensions may provide some insights about certain cultural dispositions, cultural values held by his sample of IBM employees, likely located in urban areas, may differ from those of people who speak different languages and live in rural areas.

Based on Hofstede's dimensions, Tanzania has a high power distance, suggesting a classroom culture that is likely more authoritative, and teachers that feel the responsibility of owning and distributing knowledge rather than a space where knowledge is co-constructed between students and teachers. Tanzania also scores low on individualism suggesting that students may feel the cultural responsibility to care for and support one another. Finally, with a low indulgence score, Tanzanian students may feel like their actions and behaviors are restricted by rules and social norms, and therefore restrain themselves from providing support for their peers, even when there is the need to, due to the fear of being reprimanded.

It is important to note that the Tanzanian educational system and norms are highly influenced by other cultures (such as formerly being under the colonizing forces of Britain and Germany, who instituted early governmental educational policies). Therefore, promoted pedagogical ideologies may not always be reflective of local help-seeking customs outside of the formal educational environment; e.g., despite being a highly collaborative culture, the classroom culture may be predominantly individualistic.

\subsection{Cultural factors that influence help-seeking and help-giving behaviors}

Cultural preferences dictate how people demonstrate their mastery of knowledge; ignoring these preferences can cause undue stress and demotivate students. One example is the use of frequent and mandatory testing to assess the knowledge gained by students in the classroom. While this practice is acceptable and effective in certain cultures, it is an atypical approaching others, e.g. in North American indigenous cultures [10]. Another educational practice whose success is dependent on culture is questioning students directly in front of their peers, implicitly causing students to compete with each other $[11,29]$. The practice poses a challenge to students whose cultural norms suggest people speak only when they feel fully prepared to do so.

Specifically related to student-teacher interactions, the debate style of discourse in Western education may be uncomfortable for students from cultures with high power distance, and those that tend to value group harmony over asserting one's individuality (as reflected in values scores in Tanzania). Students from Western cultures tend to take a more active role in their learning through participating and questioning the teachers, even without mastery of the subject, while students from high power distance cultures may prefer passively receiving instruction and participate when they have achieved mastery [42]. The desire to promote harmony may cause students from collectivist cultures discomfort when forced to express their opinions - students may also be apprehensive of making mistakes or making others feel uncomfortable [6, 35-37]. 


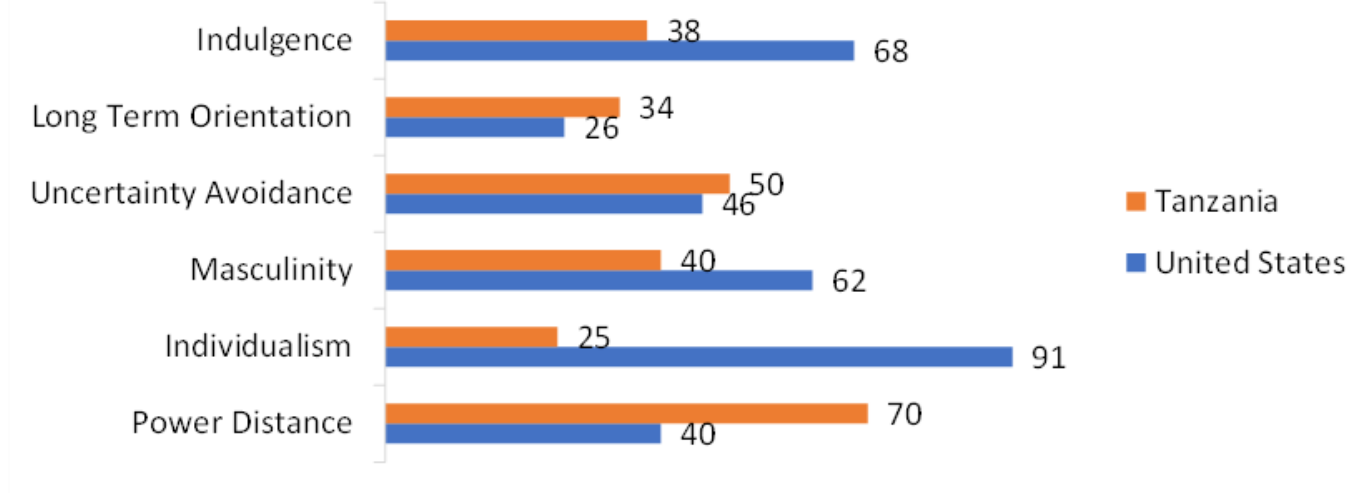

Figure 1: Hofstede's scores for Tanzania (Orange) vs the United States (Blue)

Other factors, such as culturally ascribed gender roles and group dynamics, may affect classroom culture [13, 19, 32]. In some cultures, males have more influence in group discussions, and have a greater chance of being elected group leader [30]. In Tanzania specifically, research studies suggest that there are clearly ascribed differences in the expectations and responsibilities that girls are given compared to boys. Meena et al. [22] report that girls have additional responsibilities in the home limiting their time for homework, and that subjects taught in schools emphasize themes that make girls subordinate to boys. Even in pretend play, children self-select to participate in activities that are in alignment with existing, culturally dictated, gender norms [2]. Teaching practices that disturb these accepted patterns of student interactions (such as promoting peer-peer help-seeking) could potentially be detrimental to the students' psychological wellbeing.

As noted above, the everyday living practices of Tanzanians have been observed to be more reflective of a culture where help-giving and collaboration is the norm. Nalkur et al. [26] report that homeless children in Tanzania, with extremely limited resources, feel an overwhelming sense of responsibility towards other homeless children. A qualitative study by Evans [12] reports that in Tanzanian households, older siblings generally have the responsibility of instructing, guiding, looking after, making money, and doing homework with their younger siblings to free up their parents for other income earning and family care activities. It is common practice for neighbors and friends to help children cook and care for their sick siblings to allow them go to school [21]. Neighbors may give children the opportunity to earn money for their school fees in exchange for doing domestic tasks. [26]. Since help-seeking and help-giving have been found to be prevalent in non-educational settings in Tanzania, educational technologies designed to foster such behaviors may especially thrive as it allows students to engage in behaviors that they routinely engage in outside school contexts. However, their success may be moderated by the beliefs of the authority figures who guide classroom culture.

\subsection{Teaching practices in Tanzania}

The classroom is an organized system of social interactions with institutional and socio-cultural norms influencing students and teachers behaviors [1]. These norms influence help-seeking and help-giving behaviors and may affect the efficacy of educational interventions if unaccounted for. For example, in certain contexts, teachers encourage children to collaborate freely with one another [14], while in others (such as some areas of Tanzania), help-seeking collaboration in the presence of a teacher is uncommon. While teachers' primary responsibility is to disseminate and facilitate learning in the classrooms, encompassing all the attributes of an effective teacher is the "knowledge, understanding, acceptance, and sensitivity to cultural and human diversity" [5]. Cultural norms can profoundly influence teaching practices [28, 31]. Research studies show that "teachers develop culturally shared ideas about what good teaching and learning look like even before they begin their teaching careers" [8], and that students who are training to become teachers already have preconceived notions about what good teaching practices are [41]. In some contexts (such as in Tanzania) for example, the teacher is likely sole authority in the classroom, students are not generally expected to speak until they have achieved mastery of the material, and teachers are generally expected to have all the answers to students' questions [3, 4, 9, 20, 30]; these pedagogical beliefs may be associated with the high power distance construct. Therefore, creating learning environments where students are expected to naturally take on leadership roles and help their peers may be more difficult in challenging in traditional learning contexts despite the benefits it may bring.

Researchers such as $[25,33]$ have provided valuable insights on the teaching culture in Tanzanian classrooms. In addition to teaching being teacher-dominated, research studies have found that loudly reciting learning facts, singing, and dancing are routine parts of the lecture in Tanzanian rural classrooms [38]. As classroom size increases, this teacher dominance also increases as it becomes impractical to effectively facilitate collaborative activities among the children. Mtahabwa et al. (2010) also found that teachers' management styles have a profound effect on the atmosphere of the classroom. They found that teachers who are less qualified (more frequent in rural areas) made excessive use of threats, rules, and disciplinary action to manage their classrooms compared to their urban counterparts, resulting in even quieter and less active 
students. The expectation of disciplinary action by classroom teachers may also be reinforced by parents who want their children to learn to uphold certain behavioral standards while learning in the classroom.

Creating education technologies that potentially violate these teaching norms may not have positive effects on student learning in a classroom environment. However, the challenges with providing high quality education and recruiting teachers in Tanzanian rural areas calls for interventions that foster students' support for one another, as a knowledgeable adult may not always be available. The potential unavailability of knowledgeable adults make it important to develop learning tools that can support students in unassisted learning environments, but also calls for an investigation of the effects of such interventions on students' behavior in the classroom if they have to navigate both traditional teacher-led, and unassisted learning spaces.

\section{METHODOLOGY}

We conducted this study in partnership with schools in a rural village in a Northwestern region of Tanzania. Members of our international research team had been working in this region for over three years to engage in a variety of projects and were familiar with the local conditions and context. Swahili was the common language in the village, and all adult participants in our study spoke Swahili fluently in addition to varying levels of English. The village had four primary schools (grades K-7) - a private school that cost $\$ 300.00$ USD per year to attend, and government schools with free tuition but for which parents were still responsible for certain fees, buying uniforms, and school supplies. In this study, we interviewed and observed classes at both the private and government schools.

The village itself was quite limited in physical and technical infrastructure. At the time of data collection, there was limited electricity and no running water in the village. Most of the devices we observed were feature phones without internet connectivity, however, several teachers owned basic Android smart phones while others communicated their desire to own one. Three different mobile network providers serviced the village with internet download speeds ranging from $120 \mathrm{Kbps}$ to $384 \mathrm{Kbps}$.

\subsection{Teacher Interviews}

We recruited and interviewed 24 primary school teachers and school administrators about their expectations for collaborative behaviors by students in their classrooms, and how education technologies could potentially improve their teaching practice. All interviews were conducted in Swahili with the help of a translator (who was born and raised in the village and was familiar with most of the teachers), except when the interviewee asked to conduct the interview in English. The translator was asked to translate all questions and responses verbatim - we asked follow-up questions when necessary. All interviews lasted about 45-60 minutes and included a brief demographic questionnaire. Teachers were compensated with the equivalent of a lunch meal voucher for their time. Consent was obtained from all teachers to interview and audio-record. We interviewed teachers from four different primary schools - three government schools with Swahili instruction, and one private school with English Instruction. Each school was managed by teachers and four administrative positions. All school administrators also teach classes in addition to their administrative duties (see Table 1). The three government schools had a student to teacher ratio of 1:99, 1:375, and 1:111 respectively, while the English instruction private school had a student to teacher ratio of 1:20.

Interview topics included an open-ended description of the teacher's educational history and experience, their motivations for working in a rural area rather than an urban city, their experiences with collaborating with their peers in their early education across knowledge levels and gender, their current attitude towards peer-peer collaboration in the classroom, and their opinions on technology's usefulness and suggestions for incorporating technology into their teaching practice. The native-speaker translator was also allowed to share their experience with collaboration and teaching during the interviews to increase rapport and the conversational format of the interview. All interviews were audio-recorded and transcribed for analysis. Three members of the team reviewed all transcripts, and identified emergent themes related to student collaboration and technology use following a thematic analysis approach. All high-level themes were triangulated with other types of data gathered during the study including debrief recordings, follow-up interviews, classroom observations, and photographs to ensure that all evidence were mutually supportive [23]. These interactions were aggregated in a shared working document and after all sessions were categorized, all members of the team reviewed the findings, discussed all areas of disagreement, and re-categorized findings where necessary. Table 2 shows the demographic information for all the interviewees in our study. This is relevant for highlighting the diversity in age, teaching experience, gender, and administrative responsibilities in our interview participants.

\subsection{Classroom Observations}

We also present insights gathered from 23 classroom sessions (across eight teachers) from the English Medium private school, and 16 classrooms sessions (across three teachers) from one government school. One researcher conducted these classroom observations to annotate all routine student interactions and default help-seeking behaviors in the presence of a teacher. We specifically annotated when students reached out to their peers for help when assigned individual work in the presence of a teacher, and whether the teacher reprimanded or praised them for attempting to collaborate on individual work. Given that each classroom in the English-medium school had about 15 to 25 students, we divided each classroom into three observation groups focusing on each group for 5 minutes at a time. We marked whenever a student in the group initiated an interaction with another student when assigned individual work by the teacher and recorded the teacher's reaction - positive, negative, ignored, or did not notice the students' interaction. We also qualitatively recorded how the teacher responded to any student interactions. An example log of a student interaction observation was as follows (names are anonymized):

The primary researcher in this study is a West African native with a $\mathrm{PhD}$ from a US university who has visited the village several times in the past and has lived in the village for at least 3 months over a 3 year period, and has conducted several studies with students and families from the village. Even with this prior 
Table 1: School Administrative Positions and their Duties - A diploma is the equivalent of a 4-yr bachelor's degree; A certificate is the equivalent of a 2-year associate's degree

\begin{tabular}{lll}
\hline Position & Required Qualification & Duties \\
\hline Head Teacher & Diploma & $\begin{array}{l}\text { Leader of the school - all the other administrators report to the Head } \\
\text { Teacher. Deploys all government/school owner initiatives and policies } \\
\text { in schools. }\end{array}$ \\
$\begin{array}{ll}\text { Deputy Head Teacher } \\
\text { Academic Master }\end{array}$ & $\begin{array}{l}\text { Certificate } \\
\text { Certificate }\end{array}$ & $\begin{array}{l}\text { Manages all academic issues including exams, timetables, teachers' } \\
\text { schedules, lesson plans, lesson notes, orders textbooks, learning }\end{array}$ \\
& materials, student attendance etc. \\
Assistant Academic Master & Certificate & Assistant to the Academic Master.
\end{tabular}

Table 2: Teacher Demographic Information

\begin{tabular}{|c|c|c|c|c|c|c|}
\hline ID & Gender & Age & Job & $\begin{array}{l}\text { Years of } \\
\text { Teaching }\end{array}$ & Subjects Taught & School \\
\hline 1 & $\mathrm{~F}$ & 30 ’s & Teacher & 4 & Science, Math & Govt 1 \\
\hline 2 & $\mathrm{~F}$ & 20 ’s & Teacher & 7 & Science, Math & Govt 1 \\
\hline 3 & M & 30 ’s & Teacher & 5 & English & Govt 1 \\
\hline 4 & M & 30 's & Teacher & 10 & All & Govt 1 \\
\hline 5 & $\mathrm{~F}$ & 50 's & Teacher & 28 & All & Govt 1 \\
\hline 6 & M & 26 & Teacher & 4 & Math, Swahili & English Private \\
\hline 7 & M & 27 & Teacher & 3 & Social Studies, Math, Geography & English Private \\
\hline 8 & M & 20 ’s & Teacher & 2 & Kindergarten - All & English Private \\
\hline 9 & M & 29 & Teacher & 2 & Swahili, Science, Civics, Science & English Private \\
\hline 10 & $\mathrm{~F}$ & 21 & Teacher & 3 months & Kindergarten - All & English Private \\
\hline 11 & M & 37 & Head Teacher & 10 & Geography, English, Social Studies & Govt 2 \\
\hline 12 & M & 30 & Teacher & 6 & Geography, Swahili, Science & Govt 1 \\
\hline 13 & M & 56 & Deputy Head Teacher & 33 & Math, Swahili & Govt 1 \\
\hline 14 & M & 48 & Academic Master & 24 & English, Social Studies, Swahili & Govt 1 \\
\hline 15 & $\mathrm{~F}$ & 27 & Teacher & 4 & Swahili, Social Studies, Civics & Govt 1 \\
\hline 16 & M & 30 & Asst. Academic Master & 4 & English, History, Swahili & English Private \\
\hline 17 & M & 29 & Deputy Head Teacher & 6 & Swahili, Science, Social Studies & Govt 3 \\
\hline 18 & M & 29 & Academic Master & 4 & All & Govt 3 \\
\hline 19 & M & 28 & Teacher & 4 & Math, Science, Social Studies & Govt 3 \\
\hline 20 & M & 31 & Teacher & 7 & Math, Science & Govt 1 \\
\hline 21 & M & 30 & Teacher & 4 & Science, Math, Swahili & English Private \\
\hline 22 & M & 27 & Academic Master & 4 & Swahil, Math, Social Studies & English Private \\
\hline 23 & M & 30 & Head Teacher & 7 & Math, English, Science & English Private \\
\hline 24 & M & 30 & Deputy Head Teacher & 5 & Math, Science & English Private \\
\hline
\end{tabular}

familiarity, we recognized that our position as adults observing students in their classrooms may have led to their behaving unnaturally, therefore we took multiple steps to try to increase students' comfort and rapport with the primary researcher. For every observation session in the English Private school, we sat at the back of the classroom and participated in all classroom activities just like students. Teachers often called on the primary researcher to answer simple questions to test their knowledge of Swahili, or to provide meaning and additional context to English words. Students often sang congratulatory songs when the researcher got questions correctly, and laughed at (and sometimes corrected) them when they got questions wrong. Every day, the researcher walked with students from their classrooms around the village during breaks and after school, and students usually spent this time teaching them Swahili, and asking them questions about living in the US and their family life. We also took the opportunity to ask students about some classroom behaviors that we did not understand. All these factors increased their comfort with the primary researcher and allowed them to behave more naturally as they became a familiar but non-authority figure in the classroom space. Students often came to them to ask for answers to questions assigned by their teachers after unsuccessfully asking their friends for help when teachers left the classroom. 
Date/Time: Oct 27, 1:30 PM Class: N2 Teacher: Mr. Ahmed Subject: Math

\begin{tabular}{|c|c|c|c|}
\hline Time & Student Name/ID & $\begin{array}{c}\text { Teacher Reaction } \\
(\mathbf{P}|\mathbf{N}| \mathbf{D} \mid \mathbf{I})\end{array}$ & Notes \\
\hline 2:00 PM & Baraka M. & $\mathrm{N}$ & Teacher tells him to face his work \\
\hline 2:02 PM & Furaha G. & $\mathrm{D}$ & $\begin{array}{c}\text { Teacher does not notice her talking; She } \\
\text { keeps pulling Rehema until she gets help }\end{array}$ \\
\hline
\end{tabular}

Figure 2: Sample observation logs - where the $P$ = positive reaction from teacher, $N=$ negative reaction, $I=$ teacher notices but ignores the interaction, and $\mathrm{D}=$ teacher does not notice the interaction.

Given the large class sizes in the government schools, this observation protocol was impractical for the teaching sessions observed at the government school. Rather than focusing on the students, we qualitatively recorded details of the teachers' instructions, if and when they incorporated peer collaboration in their teaching practice, as well as any difficulties they faced teaching such a large classroom. All classroom observation notes were handwritten, and an audio recorder was used to capture teacher-student interaction at the researcher's discretion. Permission was taken from the head teacher, the academic master, and the classroom teacher before we began all observation sessions. Students were also informed of our presence and were asked to welcome us to join their classrooms in both schools. At the end of each day, we reviewed all audio recordings and discussed observation notes with a native speaker for translation into English when necessary as well as their insights on data gathered to provide additional context. Finally, we audio recorded all classroom observation notes, additional reflections and review meetings with the native speaker daily for future transcription and analysis.

Three members of the team reviewed all classroom observations, and identified emergent themes related to student collaboration and teaching practices following a thematic analysis approach [7, 23]. All the high level themes were triangulated with other types of data gathered during the study including debrief recordings, follow-up interviews, and photographs to ensure that all evidence were mutually supportive [23], and to generate a definitive list of themes for further analysis. These transcripts were analyzed using a Qualitative Data Analysis tool (Atlas.TI) to categorize the observation transcripts into the agreed upon themes to uncover all interactions related to student collaboration, collaborative teaching methods, and other classroom practices using a Thematic Analysis approach. Insights from data gathered from these classroom observations were used to understand normal student-student, and teacher-student interactions and collaborative behavior in the classrooms.

\section{FINDINGS}

\subsection{RQ 1: What are the socio-cultural ideologies that influence teachers' disposition towards peer-peer collaboration in rural Tanzania?}

4.1.1 Government policies highly influence teachers' attitudes towards peer-peer collaboration. We asked teachers about their experiences with peer collaboration while growing up. All teachers except four shared that their teachers supported collaboration; they had taken this approach when they realized that students needed additional help beyond what they could provide or when their position as authority figures prevented the students from asking them questions.

When I was in primary school, teachers only wanted us to work by ourselves. When they realized that students were unable to understand, though, they started using group discussions to allow students share ideas.

Teacher 16.

The interviewees whose teachers supported collaboration stated that it was beneficial for students learning to include collaboration in the classroom, however, this collaboration had typically only been allowed when purposefully designed by the teacher rather than naturally initiated by students. When students were caught collaborating outside of planned activities, they were often punished with being asked to prove their knowledge to the whole classroom, their seats were switched, or they were reprimanded with sticks. Teachers stated that collaboration activities usually took the form of discussions with other students at the beginning of a topic.

The four teachers (teachers $5,11,13,14$ ) that did not have any experience with collaboration growing up all had more than 10 years' experience and explicitly said the government did not permit their teachers to include collaboration at the time.

They (teachers) did not allow us to cooperate when I was growing up. I went to school in the 80's ... at the time, the education policy does not allow students to cooperate. A teacher comes into the class and teaches students and all the students take notes. Right now, the education policy tells us to use the participation method.

Teacher 11 .

No - my teachers did not allow us to collaborate. I am not sure of the reason why they did not support this - I think it was the policy that teachers had to do all the teaching in the school. I can remember only a few cases where collaboration happened... in the Kiswahili subject when students do not understand how to read 
and might ask other students to read so they hear... but it happened very rarely.

\section{Teacher 14.}

The influence that government policies have over teaching practices in Tanzania cannot be underestimated. Teachers stated that a government job meant guaranteed income, medical and continued education benefits, as well as social security income after their retirement at sixty-five years old. One teacher mentioned that the government heavily subsidizes the cost of obtaining a teaching certificate with the expectation that teachers will work for the government schools in return. After teachers graduate, the government assigns them to teach in any part of the country that needs more teachers without their input. Teachers are aware of this and are happy to receive a government posting even if they were unhappy with the physical conditions of their place of assignment. When asked, all the government schoolteachers stated they would not leave the government teaching job for a private school even for double the salary and smaller class sizes. However, they acknowledged that education in the private school was of a higher quality than the government school due to the smaller class sizes - three government schoolteachers we interviewed sent their children to the private school for education. The private school teachers shared the same sentiment $-8 / 10$ stated that they would leave their jobs for a government job even for half the salary and five times the number of students. The main reason stated was that their salaries in the private schools depended entirely on parents' ability to pay, and factors such as bad weather or planting seasons often determined whether or not they received their salaries, unlike the guaranteed income at the government schools.

Finally, [20] reports an issue of frequent teacher absences in Tanzanian primary schools. Teachers in our interview provided some context for this issue noting that they are often called to the government district office for training, and that they assist in nation-wide government-run initiatives such as elections and the census, noting that the government influences their ability to attend classes.

4.1.2 Teachers support peer collaboration but only when they design and scaffold the interactions. This experience with collaboration and the current government policy influenced teacher's current attitudes towards peer-peer collaboration in their classrooms. Most teachers interviewed (21/24) stated that they currently support classroom collaboration because students might be more comfortable around one another and teaching in large classrooms necessitates the use of group activities.

Yes because sometimes when teachers teach, students do not understand them totally because of many factors. Students fear them or other factors. But when students discuss with other students, they understand because they are used to each other, and the language they use is like the informal language. They use vernacular languages so one can mix with another language to make the other student understand.

Teacher 1 .
Sometimes students do not understand teachers but they understand themselves so I support this. In my experience, students in the same age group can be different in their understanding. Some students understand fast, others are slow learners. It is all about the IQ... some are high and others are low. Some cannot understand as fast as the teacher teaches. It takes time to serve these large classes. ... My class has over 100 students. That is why sometimes students don't understand. Even with grouping the students, I can not serve all the groups in a day.

Teacher 5 .

Teachers who did not support collaboration discussed their need to monitor students' individual knowledge, and that collaborative activities did not let them assess students individually. This need was expressed by teachers who supported collaboration - most $(19 / 21)$ stated that they only allowed collaboration in an activity that was designed and coordinated by them. These teachers explicitly stated that they regarded it as cheating when students collaborated on individual work even if it was just a practice exercise and not a test/exam, and punished students using similar methods as their teachers.

When planning collaboration groups, teachers stated that they ensured that all groups had a mix of both boys and girls as it was the government's policy to prevent gender segregation. All teachers and administrators (except the Head Teacher of the private school) also ensured that each group had a mix of students that they perceived as high achievers, and students who needed additional help. This grouping strategy was teachers' way of ensuring that that struggling students had someone to help them - the teachers often chose the high achieving students as the leaders of each group.

Sometimes I select the group leader, other times I allow the students select their group leader. The most important thing is that the leader of the group is bright.

Teacher 11

While teachers perceived this grouping strategy to be effective for peer collaboration, they acknowledged that it may have negative psychological effects on the students who are struggling.

No.... the less brilliant students are afraid of the brilliant students... they cannot help them with anything. [Q: what about experiences like with herbs or animals or with money?] No.... [teacher laughs]... It is not possible for the less brilliant students to teach anything because they are afraid of the brilliant students. Even if they know something, they cannot say it.

Teacher 11.

In academic issues, it is very difficult for this (struggling students to speak up) to happen because he is afraid of the brilliant students... he doesn't feel that he can say that this is correct or this is wrong for the brilliant students ... he just accepts whatever the brilliant students says. . . but in things like sports or environmental issues and other issues outside the class maybe it is possible.

Teacher 17. 
Table 3: Description of group activities observed in the classrooms.

\begin{tabular}{|c|c|c|}
\hline Teacher ID & Grade & Description of Collaborative Activity \\
\hline Teacher 5 & Nursery & $\begin{array}{l}\text { Lesson on primary colors. She divides the class into four groups and hands each group a different } \\
\text { colored ball. She calls each group by their color name and asks them to perform a different motion e.g. } \\
\text { jump, walk forward and backwards, dance etc. Sometimes she hands all colored balls to students } \\
\text { within one group and asks them to perform the different motions, switching colors often, while the } \\
\text { other students watch. This exact group activity was repeated in another session. }\end{array}$ \\
\hline Teacher 6 & Primary 1 & $\begin{array}{l}\text { Lesson on the addition of two-digit numbers. He wrote a question on the chalk board: } 43+24 \text {. He } \\
\text { called four students to the front of the class - one student to draw three balls, the second to draw four } \\
\text { balls, the third to count all the balls, and the fourth to write the answer in the digit form. Most } \\
\text { students raised their hands for the chance to write on the board. He reviewed each problem after it } \\
\text { was completely solved. }\end{array}$ \\
\hline Teacher 6 & Primary 3 & $\begin{array}{l}\text { (Activity occurred the day after teacher interview). Lesson on representing word problems using } \\
\text { pictograms. He started by sitting children in different mixed-gender groups. Then he wrote a question } \\
\text { on the board with different students' names in one column and drew the corresponding number of } \\
\text { flowers each student had in the adjacent column. He asked each group a different question e.g. "which } \\
\text { student has the least?", "how many flowers do all the students have?" etc. Students in the groups he } \\
\text { picked raised their hands, and he called on one student to respond. After this activity was over, he } \\
\text { asked the students to return to their seats and he gave them a quiz at the end of the class. }\end{array}$ \\
\hline Teacher 14 & Primary 2 & $\begin{array}{l}\text { Lesson on words and their opposites. He invited a few students to the front of the classroom. He then } \\
\text { asked the whole class, "what is the opposite of tall"? They all said "short". He asked the class to point } \\
\text { to all the tall students in front, and all the short students as well. All the students participated, and } \\
\text { they all enjoyed this activity. He invited other students from the class to suggest other words e.g. fast, } \\
\text { hungry etc. and asked the students in front to act out the opposites. }\end{array}$ \\
\hline Teacher 14 & Primary 3 & $\begin{array}{l}\text { (Activity occurred the day after teacher interview) Lesson on animals and their babies. He started by } \\
\text { calling on students who are high achievers in his class and moving them to other tables in the class - } \\
\text { he informed them that they are the group leaders. Then he held up his phone in front of class and } \\
\text { played a YouTube video on baby animals as students took notes. Afterwards, he told students to write } \\
\text { down all the animals and their babies from the video. Students started doing this work individually, } \\
\text { but he told them to discuss with one another and come up with answers together. Students began } \\
\text { talking to one another in whispers. Shortly after, he leaves the class and students started discussing } \\
\text { loudly and moving around the classroom coming up with answers. After about five minutes, he } \\
\text { returned to the class and they immediately returned to their seats. He called on each assigned group } \\
\text { leader to present the work from their group. }\end{array}$ \\
\hline
\end{tabular}

We observed practices in the private school classrooms that may reinforce the apprehension that low achieving students feel regarding answering questions that they are unsure of. When students answered questions after being called upon by the teacher, their peers sang a 'shame' song if they answered a question incorrectly, "Shame shame shame... shame upon you... a very big boy/girl", or a song of praise if they answered questions correctly, "well done well done. . . try again another day... a very good boy/girl." While we did not interview students on how the 'shame' song made them feel, it may partially explain their unwillingness to speak up in group learning situations with higher achieving students present.

\subsection{RQ 2: How are peer-peer collaborative practices demonstrated (if at all) in rural Tanzanian classrooms?}

4.2.1 Teachers rarely incorporate collaborative activities in their teaching practice. Although most teachers stated that they support students working together, we observed only 6/39 sessions where teachers incorporated collaborative activities in their classroom practice. Two of those collaborative sessions occurred the day after we interviewed the teachers. Table 3 shows a description of the collaborative activities we observed.

The remainder of the teaching methods most commonly used depended on the age group of students and the class size. Teachers in nursery (kindergarten) classrooms commonly used songs, dance routines, and had their students repeat after them often. In the private school, there was a lot of individualized attention on students, and students were sometimes rewarded with small gifts like pencils for answering tough questions. Teachers often walked around the nursery classrooms inspecting student notebooks and correcting errors, ruling margins in their notebooks, holding students' hands to teach them handwriting, and even helping them with obtaining writing materials. In the primary schools, teachers rarely used songs to teach, but employed mainly lecture-style instruction and rote repetition. Teachers routinely connected their content to contexts that students were familiar with. In a lesson about soil erosion, one teacher in the private school pointed to the road outside their classroom as an example, and called on students whose fathers were 


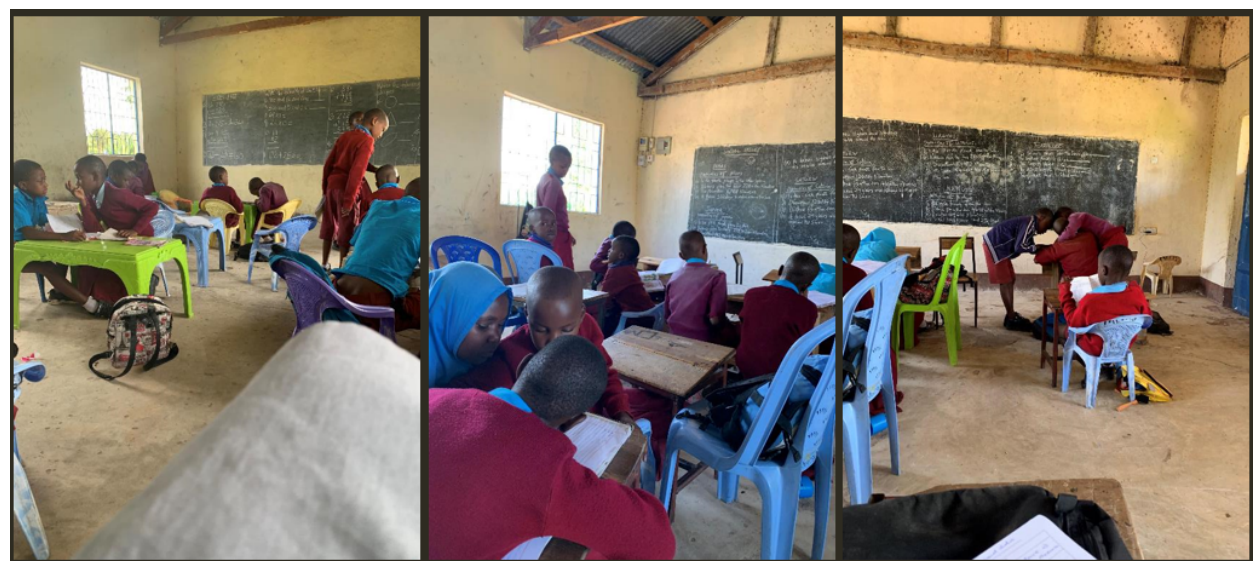

Figure 3: Students collaborating in the absence of a teacher in private school classrooms.

farmers to explain the concepts of over-grazing and cutting down trees to students. As expected, this sort of individualized attention was impossible in the government school with the large class sizes. Teachers mainly lectured for the entire class period, ending with practice exercises that they then collected for grading.

4.2.2 Students get reprimanded by teachers for collaborating with one another outside of planned group activities. In the private school, students collaborated very openly with one another on practice exercises every time teachers left their classroom. Students collaborated across age and gender, and across academic ability. They sometimes collaborated discretely while the teacher was still in the classroom but were reprimanded when the teacher caught them. Altogether, we recorded 39 incidents of students reaching out to their peers for help in the presence of a teacher: 24 of those incidents appeared to go unnoticed by the teacher, 12 times the teacher noticed and reprimanded the students either by telling them to work alone or switching their seats, and there were 3 incidents where the teacher noticed but ignored the student. Students used different techniques to disguise their need to collaborate including pretending to borrow writing materials from their friends and whispering when the teacher had their back turned to them.

Teachers' primary concern regarding students collaborating on individual activities was that they assumed that students simply copied answers to practice questions from their peers. When asked about why he thought collaboration on individual exercises was bad, teacher 21 responded, "cheating is bad. It means they don't understand it. That can make them fail... if they copy you won't know who knows it." As teachers suspected, we observed several incidents of students copying answers from their peers. However, contrary to teachers' beliefs, students collaborated in more ways than just asking their peers for answers. In the private school with English instruction, students sometimes did not understand the instructions of some class exercises that they were given. We observed two instances where students went to their friends to ask for help translating the questions into Swahili so they could answer it on their own. Students very often worked on problems on their own but verified their answers with their peers before turning in their notebooks for grading. This behavior of confirming answers before submission was more common among students who were the high achievers in the classroom, irrespective of gender. There were two instances where high achieving students reported their lower achieving peers to us for trying to copy their answers; however, they did not complain when their higher achieving peers engaged in the same behaviors. Finally, of the 39 instances of collaboration, 12 of them involved students discussing questions, and reading their notebooks together while searching for answers to practice questions.

\subsection{RQ 3: What challenges do teachers and students experience in this learning context that might impact the deployment of peer-peer collaborative technologies?}

4.3.1 Large classes reduce student-instructor interactions. One of the major issues reported from previous studies about public education in Tanzania is that there are very large numbers of students with few teachers to support them. This study is no exception the teacher to student ratio in the government schools in our study ranged from 1:99, to one school having only one teacher to support over three hundred students. Combining these large class sizes with working in villages with limited resources and a higher number of struggling families, teachers have learned to accept that they cannot possibly support all students in their classroom and spend a lot of time on non-teaching activities at the expense of learning time.

In one class session observed, a government schoolteacher was giving a lecture about parts of the body to primary 1 students. $\mathrm{He}$ asked the students to draw a stick figure in their notebooks and come up to him for grading before he began the lecture. It took the teacher the entire class period to grade the stick figure of the over 150 students present in the class that day - he never got to the main lecture before he had to leave. Several students did not have writing materials and he had to help them find extra pencils in and out of the classroom to allow them to participate in the classroom activity. In another class observation, the teacher was instructing the students to say numbers greater than one hundred. 


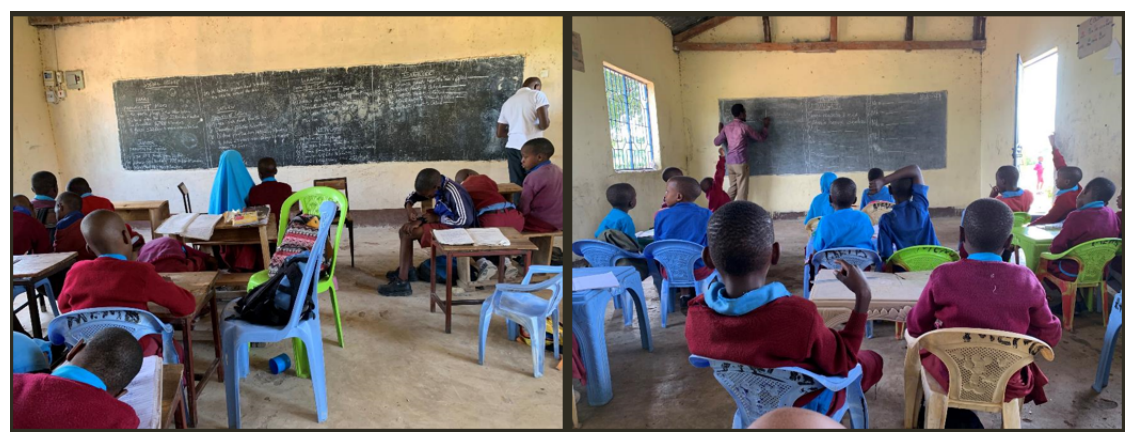

Figure 4: Student behavior in the presence of a teacher

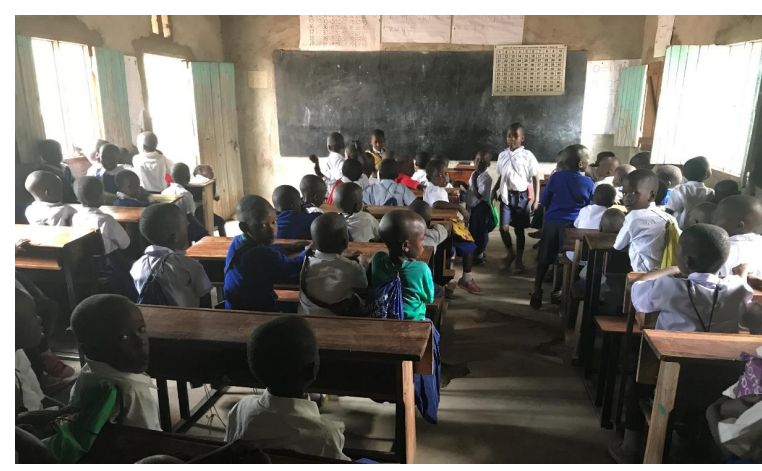

Figure 5: Large class sizes in government schools

She called each number and the students repeated after her. She noticed that only the students in front were paying attention and responding while those at the back either mumbled responses or were completely silent. She responded by focusing on the students in front.

When we asked how they would deploy educational technology, assuming unlimited resources, all teachers mentioned that such large classes make it impractical to deploy these technologies one on one with students.

Even if we have the tablets for free, there will be a problem with noise. Everyone will open a different program and you can't control it.

Teacher 15.

The number of students in large classes will make this really hard to manage. I prefer the use of projectors. When there is one tablet per student, I am not really sure of how to use the technology. . it means that I have to figure out a way to monitor all of them. I will be giving a lecture in the class and students are just clicking away.... [ ${ }^{*}$ thinks for a while $\left.{ }^{*}\right]$.. I can't really see a way to use this if all students have it one by one.

\section{Teacher 14}

These responses indicate a concern about the reduction in classroom control that teachers would experience if instruction became individualized. While this concern has been noted by teachers in other research on personalized learning technologies, the classrooms in our sample were an order of magnitude larger than most classes in Western studies of such technology. Teachers described how they could address these class size challenges by dividing the class into smaller groups and either giving only one tablet to a group of students to use together or restricting the technology to use by one group at a time, in order to allow them to better manage student-technology interactions. Such approaches to deployment could afford opportunities to introduce collaboration scaffolds within the technology while simultaneously increasing teachers' perceptions of control over the technology-enhanced environment.

4.3.2 Infrastructural challenges in rural areas. After discussing the topic of peer-peer collaboration with teachers, we posed a hypothetical question: "If I offered you 100 million Tanzanian Shillings to improve education in this village, what are the top 5 things that you would spend the money on?" All teachers mentioned building more classrooms as the most pressing need in their school. Other items frequently mentioned included electricity in schools, food for students, housing for teachers and sufficient learning materials including textbooks and writing materials for students. None of the government schools in our study had electricity; the fastest mobile internet download speeds ranged from $120 \mathrm{Kbps}$ to $384 \mathrm{Kbps}$. Without a dedicated Wi-Fi connection or guaranteed power, charging or updating technological devices may be impossible.

We asked teachers this question after presenting them with a demo of a tablet-based collaborative learning system. All teachers reported a belief that this system would be beneficial for their teaching practice. When asked to expand on why technology was not on their priority list some teachers did adjust their list to include technology among their list of teaching materials, while others reported that they believed their schools had more pressing needs despite the potential of technology. This mixed response notwithstanding, all teachers could imagine ways in which education technologies could help alleviate some of the problems they experienced with teaching infrastructure and resources in rural areas. Several teachers suggested that technology can help to automate grading and allow them more teaching time. Others said technology could help them ensure that all students had some form of instruction when they were unavailable to teach, opening new opportunities for collaboration in a context in which learners may feel less constricted by authoritative classroom norms. 
4.3.3 Technology as a novel yet increasingly essential medium for work and school. Teachers also described additional opportunities for technology to enhance their classroom that went beyond solving infrastructure challenges. Several mentioned that the novelty of technology will prompt students to be more punctual at school. Teacher 5 compared the novelty of education technologies to a reading intervention that a teacher recently created at the school:

Like the primary 2 teacher, he has created like a machine for reading. When he holds it up, it comes out like 'ba bi be bu' so all the students can be surprised and read what comes out. No student is missing the class because they want to see the machine work. It is the same with the computer - all students will come to school because of the technology.

Teachers also discussed the potential of education technologies to better prepare their students for an increasingly globalized world and help students with a better understanding of the subjects they currently teach. All schools that our interview participants worked for had an Information and Communications Technology (ICT) subject as part of the school curriculum. However, teachers had resorted to only showing students pictures of computers and other technologies, admitting that students do not have a full understanding of how such systems work.

For the older students, there is a subject in primary 6 and 7 where the children are supposed to learn how to use technology. Teachers are supposed to teach students about laptop and desktop and show the students but they don't have them so they teach theoretically. Technology will be helpful for those... There was another subject [taught in the school] called broadcasting and communication that failed because there were no materials to teach the students. It was about technology and phones and other communicative devices, but they had no way to demonstrate to the children and therefore stopped the class.

Teacher 14.

With the technology in this time of globalization, in a few years, they will need to know how to use these technologies to get employment, so we have to teach them. Even the materials we teach now, like if you are the ICT teacher, we can teach them practically instead of just theoretically.

Teacher 3 .

\section{DISCUSSION}

Our research provides additional nuance to previous studies, showing that although teachers in our sample do not routinely incorporate collaborative activities in their teaching, they do believe that peer collaboration leads to improved learning for students - sometimes in contrast to their own educational experiences as students. They indicated that it was important for teachers to have control over collaborative interactions and that it should only happen at the times and activities indicated in order to prevent negative outcomes. While we found that teachers did not frequently support unstructured peer collaboration in their current classrooms, neither are they opposed to the idea of students teaching one another when properly scaffolded (opposition which has been implied by previous research studies, e.g. [33]), and may be open to curriculum changes that help them create and manage collaborative activities better. Teachers were also already familiar with some pedagogical techniques that incorporate collaboration, which we observed mainly in the class sessions directly following our interviews on collaboration. As noted above, these findings demonstrate the possibility of change in cultural values and practices that can occur over time.

Our findings also remind us that this change may be linked to shifts in government and national education policies which should be understood before introducing any educational interventions. Teachers indicated that collaboration was a part of the pedagogical technique currently being promoted within government training. This was a shift from prior decades in which it had been discouraged by the government, leading to a divide among more novice and more experienced teachers. Gender equity and its impact on collaboration processes like group formation was also a newer concern that arose from governmental influence.

Additionally, we found that with the job security and benefits of government jobs in Tanzania, teachers in rural areas are likely to continue seeking the financial stability of teaching in government schools with large class sizes and limited resources rather than the financial uncertainty of teaching in private schools, even with more ideal teaching conditions. As highlighted in our findings, these large class sizes in rural Tanzania make one-to-one technology interventions impractical for teachers to manage. Researchers must therefore navigate designing interventions suitable for managing very large classroom sizes with limited manpower to manage those interventions.

Together, these insights suggest that researchers and educational practitioners have the opportunity to support teachers in such rural classrooms with practices and teaching methods that incorporate the social and cognitive benefits of peer collaboration, while also respecting their authority in the classroom, which teachers viewed as essential to good teaching. We found that teachers believed in the potential of educational technologies to make a positive difference in their classrooms for a variety of reasons, and in particular suggested collaborative uses of technologies as a preferable solution to individual use. Such a paradigm aligns with their preferences for promoting peer language [27] within a hierarchical classroom structure and in controlled, scaffolded activities. These challenges open the opportunity to design education technology solutions suitable for small groups of students rather than individuals. This is not to say that popular models of deploying educational technologies one-on-one with students in classrooms will not work in this context. However, more successful solutions could challenge the conventional design paradigms of personalized learning technologies to adapt for use by multiple students while still maintaining the learning benefits of individual devices, drawing on or expanding paradigms from the Computer-Supported Collaborative Learning community.

Even so, it is important to include the caveat that many communities face significant hurdles that may hinder the adoption or deployment of even the most effective technologies. Infrastructural challenges such as a lack of power, security, and internet make the costs of maintaining devices for students prohibitive for already 
struggling schools. As evidenced in the teacher to student ratios in our study, there is a shortage of teachers to teach students even basic subjects. Even though technology has the potential of making the teaching of those basic subjects more effective, school administrators may not dedicate already scarce resources to new initiatives rather than traditional teaching methods that they perceive to be effective. Given these limitations, researchers and practitioners must think very critically about the feasibility of educational interventions.

\section{CONCLUSION}

Educational technologies (EdTech) interventions targeted at African communities are often based on solutions proven to work in the Global North. Even when "localized", broad generalizations are made about African culture and present problems in monolithic terms - justifying the need for interventions using statistics aggregated over the entire continent. These statistics often do not distinguish between important deployment contexts such as urbans vs rural areas, private vs public schools, or investigate how cultural values and deployment contexts intersect and affect the efficacy of EdTech solutions. Instead, the views of key stakeholders e.g. teachers and local custodians of knowledge should be presented and cultural ways of learning could be prioritized, supplanting experimental interventions without long-lasting benefits to the local communities. In our study, we interviewed 24 teachers and administrators, and observed 39 classroom sessions in a rural village in Tanzania to explore whether and how EdTech that fosters peer-peer collaboration can be utilized given the teaching context. We reveal insights that highlight the importance of government policy, perceptions of authority in the classroom while students collaborate, the impracticality of deploying one on one EdTech in public schools, and how infrastructural and human resource challenges can limit or enhance the success of EdTech.

\section{REFERENCES}

[1] Ädel, A. 2011. Rapport building in student group work. fournal of Pragmatics. 43 , 12 (2011), 2932-2947.

[2] Berinstein, S. and Magalhaes, L. 2009. A study of the essence of play experience to children living in Zanzibar, Tanzania. Occupational therapy international. 16, 2 (2009), 89-106.

[3] Biggs, J.B. 1996. Learning, schooling, and socialization: A Chinese solution to a Western problem. Growing up the Chinese Way: Chinese Children and Adolescent Development. S. Lau, ed. The Chinese University Press. 147-167.

[4] Biggs, J.B. 1996. Western misperceptions of the Confucian-heritage learning culture. The Chinese Learner: Cultural, Psychological and Contextual Influences. D.A. Watkins and J.B. Biggs, eds. CERC and ACER. 45-67.

[5] Chau, K.L. 1990. A model for teaching cross-cultural practice in social work Journal of Social Work Education. 26, 2 (1990), 124-133.

[6] Cocroft, B.A.K. and Ting-Toomey, S. 1994. Facework in Japan and the United States. International fournal of Intercultural Relations. 18, 4 (1994), 469-506.

[7] Corbin, J. and Strauss, A. 2008. Basics of qualitative research: Techniques and procedures for developing grounded theory. Thousand Oaks. (2008).

[8] Correa, C.A., Perry, M., Sims, L.M., Miller, K.F. and Fang, G. 2008. Connected and culturally embedded beliefs: Chinese and US teachers talk about how their students best learn mathematics. Teaching and Teacher Education. 24, (2008), 140-153. DOI:https://doi.org/10.1016/j.tate.2006.11.004.

[9] Degen, T. and Absalom, D. 1998. Teaching Across Cultures: Considerations for Western EFL Teachers in China. Hong Kong Journal of Applied Linguistics. 3, (1998), 117-132.

[10] Demmert, W., Grissmer, D. and Towner, J. 2006. A review and analysis of the research on Native American students. Journal of American Indian Education. 45 , 3 (2006), 5-23.

[11] Deyhle, D. and Swisher, K. 1997. Chapter 3: Research in American Indian and Alaska Native Education: From Assimilation to Self-Determination. Review of research in education. (1997).
[12] Evans, R. 2012. Sibling caringscapes: Time-space practices of caring within youthheaded households in Tanzania and Uganda. Geoforum. 43, 4 (2012), 824-835.

[13] Halimi, M., Consuegra, E., Struyven, K. and Engels, N. 2016. The Relationship Between Youngsters' Gender Role Attitudes and Individual, Home, and School Characteristics. SAGE Open. 6, 3 (2016), 1-19. DOI:https://doi.org/10.1177/ 2158244016656230 .

[14] Halloluwa, T., Vyas, D., Usoof, H. and Hewagamage, K.P. 2018. Gamification for development: a case of collaborative learning in Sri Lankan primary schools. Personal and Ubiquitous Computing. 22, 2 (2018), 391-407.

[15] Hartup, W.W. 1992. Having Friends, Making Friends, and Keeping Friends: Relationships as Educational Contexts. ERIC Digest. (1992).

[16] Henderson, L. 1996. Instructional design of interactive multimedia: A cultural critique. Educational technology research and development. 44, 4 (1996), 85-104.

[17] Hofstede, G. 2001. Culture's Consequences: Comparing values, behaviors, institutions. SAGE Publications.

[18] Hofstede's Country Comparisons: 2017. https://geert-hofstede.com/countries. html. Accessed: 2017-06-21.

[19] Kane, E.W. 2000. Racial and ethnic variations in gender-related attitudes. Annual Review of Sociology. 26, 1 (2000), 419-39.

[20] Lee, W.O. 1996. The cultural context for Chinese learners: Conceptions of learning in the Confucian tradition. The Chinese Learner: Cultural, Psychological and Contextual Influences. D.A. Watkins and J.B. Biggs, eds. CERC and ACER. 25-41.

[21] LeVine, R.A., Dixon, S., LeVine, S., Richman, A., Keefer, C.H., Leiderman, P.H. and Brazelton, T.B. 1996. Child care and culture: Lessons from Africa. Cambridge University Press.

[22] Meena, R. 2018. Situational analysis of education of girls/women in Tanzania. Utafiti fournal. 3, 2 (2018).

[23] Merriam, S.B. and Merriam, S.B. 2009. Qualitative research: a guide to design and implementation. Jossey-Bass.

[24] Msaki, E. 2006. THE UNITED REPUBLIC OF TANZANIA MINISTRY OF EDUCATION AND VOCATIONAL TRAINING Education Sector Development Programme. (2006).

[25] Mtahabwa, L. and Rao, N. 2010. Pre-primary education in Tanzania: Observations from urban and rural classrooms. International fournal of Educational Development. 30, 3 (2010), 227-235.

[26] Nalkur, P.G. and Orientations, A. 2009. Strategies: A Cultural Comparison of Tanzanian Street Children, Former Street Children, and School-Going Children. Journal of Cross-Cultural Psychology. 40, 6 (2009), 1014.

[27] Paugh, A.L. 2020. Peer Language. The International Encyclopedia of Linguistic Anthropology. (2020), 1-5.

[28] Pepin, B. 2002. Different Cultures, Different Meanings, Different Teachings. Teaching Mathematics in Secondary Schools: A Reader. L. Haagarty, ed. Routledge. 245258.

[29] Phillips, S. 1983. The invisible culture. Communication in classroom and community. (1983).

[30] Phuong-Mai, N., Terlouw, C. and Pilot, A. 2005. Cooperative learning vs Confucian heritage culture's collectivism: Confrontation to reveal some cultural conflicts and mismatch. Asia Europe fournal. 3, 3 (2005), 403-419. DOI:https://doi.org/10. 1007/s10308-005-0008-4.

[31] Remillard, J., Van Steenbrugge, H. and Bergqvist, T. 2014. A Cross-Cultural Analysis of the Voice of Curriculum Materials. International Conference on Mathematics Textbook Research and Development (2014), 395-400.

[32] Singh, N., Zhao, H. and Hu, X. 2005. Analyzing the cultural content of web sites: A cross-national comparision of China, India, Japan, and US. International Marketing Review. 22, 2 (2005), 129-146. DOI:https://doi.org/10.1108/02651330510593241.

[33] Stambach, A. 1994. "Here in Africa, We Teach; Students Listen": Lessons about Culture from Tanzania. Journal of Curriculum and Supervision. 9, 4 (1994), 368-85.

[34] Stone, S.J. and Christie, J.F. 1996. Collaborative literacy learning during sociodramatic play in a multiage (K-2) primary classroom. fournal of Research in Childhood Education. 10, 2 (1996), 123-133.

[35] Ting-Toomey, S. 1988. Intercultural conflict styles: a face-negotiation theory. Theories in intercultural communication. Y. Kim and W. Gudykunst, eds. SAGE. 213-235.

[36] Ting-Toomey, S. 1988. Rhetorical sensitivity style in three cultures: France, Japan, and the United States. Central States Speech fournal. 39, 1 (1988), 28-36. DOI:https: //doi.org/10.1080/10510978809363232.

[37] Tsui, A. 1996. Reticence and anxiety in second language teaching. Voices from the language classroom. K. Bailey and D. Nunan, eds. Cambridge University Press. 145-167.

[38] Uchidiuno, J., Yarzebinski, E., Keebler, E., Koedinger, K. and Ogan, A. 2019. Learning from african classroom pedagogy to increase student engagement in education technologies. Proceedings of the Conference on Computing \& Sustainable Societies (2019), 99-110.

[39] Uchidiuno, J., Yarzebinski, E., Madaio, M., Maheshwari, N., Koedinger, K. and Ogan, A. 2018. Designing Appropriate Learning Technologies for School vs Home Settings in Tanzanian Rural Villages. Proceedings of the 1st ACM SIGCAS Conference on Computing and Sustainable Societies (2018), 9.

[40] Ushioda, E. 1996. Learner autonomy 5: The role of motivation. Authentik. 
[41] Wilson, S.M. 1990. The Secret Garden of Teacher Education. Phi Delta Kappan. 72, (1990), 204-209.
[42] Xiao, L. 2006. Bridging the gap between teaching styles and learning styles: a cross-cultural perspective. Teaching English as a Second or Foreign Language. 10, 3 (2006), 1-15 